\title{
Tribological study of hot pressed oxide dispersion strengthened 2205 DSS composite
}

\author{
Estudio tribológico de prensado en caliente de compuesto 2205 DSS \\ reforzado por dispersión de óxido
}

O. Olaniran ${ }^{*, * *}$, P. A. Olubambi*, J. H. Potgieter***, J. A. Omotoyinbo**, B. A. Obadele* , A. Andrew*

\section{ABSTRACT}

This work studied the influence of ceramic oxide on the tribological behavior of hot pressed 2205 DSS composites with varying percentage composition of partially stabilized zirconia (PSZ) and alloying elements; crome (Cr) with nickel (Ni) developed by PM route. The experiment was conducted with a tribometer by ball on disc under the following parameters: WC ball of $5 \mathrm{~mm}$ as the counterbody, sliding load of $15 \mathrm{~N}$ and sliding distance of $2 \mathrm{~mm}$ at room temperature under dry condition. Wear tracks of the worn surface were examined with Scanning Electron Microscope (SEM); JEOL JSM-7600F with Energy Dispersive X-ray Analysis (EDX) attachment. The results revealed that small amount of PSZ could enhance wear resistance of the composite. EDX spot analyses indicated that there were transferred layers of tungsten (W) on the worn surface. Coefficient of friction (COF) and Taber Index were used to evaluate the wear property of the composites. It was found that sample with $0.5 \% \mathrm{PSZ}, 0.81 \% \mathrm{Cr}$ and $0.19 \% \mathrm{Ni}$ has the best wear resistance.

\section{RESUMEN}

Este trabajo estudia la influencia de óxido cerámico en el comportamiento tribológico de materiales compuestos 2205 DSS de prensados calientes con una composición variable de porcentaje de partially stabilized zirconia (PSZ) y elementos de aleación; cromo (Cr) con niquel (Ni) desarrollado por ruta de pulvimetalurgia (PM). El experimento se realizó con un tribómetro de bola sobre disco, bajo los siguientes parámetros: Bola WC de $5 \mathrm{~mm}$ como contra cuerpo, carga deslizante de $15 \mathrm{~N}$ y $2 \mathrm{~mm}$ de distancia deslizante a temperatura ambiente en condiciones secas. Las huellas del desgaste de la superficie desgastada fueron examinados con Scanning Electron Microscope (SEM); JEOL JSM-7600F con Energy Dispersive X-ray Analysis (EDX) adjunto. Los resultados revelaron que una pequeña cantidad de PSZ puede amplificar la resistencia al desgaste del material compuesto. Los análisis EDX puntuales indicaron que habia capas transferidas de tungsteno (W) en la superficie desgastada. Se utilizaron indices de coeficiente de fricción (COF) y Taber para evaluar la propiedad de desgaste de los materiales compuestos. Se encontró que la muestra con 0.5\% PSZ, $0.81 \%$ de Cr y $0.19 \%$ de Ni tiene la mejor resistencia al desgaste.

\section{INTRODUCTION}

Oxide Dispersion Strengthened (ODS) steel fabricated by powder metallurgy technique present excellent mechanical strength at high temperature (Ming, Zhagjian, Pei, Lu, Yingli \& Changchun, 2010). Powder metallurgy allows composite materials, notably metal-ceramic composites, to be produced by sintering a mixture of powders. Parameters such as temperature and pressure, particle size and shape, particle distribution, powder composition and grades have a great influence on the powder metallurgy processing and properties of the stainless steel (Zhoungchun, Takenobu, Keisuke \& Tadasu, 2000; Sulima, Klimczyk \& Hyjek, 2009; Campos, Bautista, Caceres, Abenojar \& Torralba, 2003). The premixes of other existing stainless steels to form another type of stainless steel are also studied by Datta \& Upadhyaya (2001).

\footnotetext{
* Chemical and Metallurgy Department, Tshwane University of Technology. Bag X680, Pretoria, South Africa. Phone: +27736193028. E-mail: dayo525@yahoo.com

** Metallurgical and Materials Engineering Department, Federal University of Technology. Akure, Nigeria.

${ }^{* * *}$ Chemistry and Materials Division, School of Biology, Chemistry and health Sciences, Manchester Metropolitan University. All Saints Oxford Road, Manchester MI SGD, UK
} 
There is a great demand for a new material to be used in engineering applications. This new materials should have high wear resistance (strength) and high temperature stability greater than that of steel (i.e. as high as possible) and at the same time, its coefficient of thermal expansion must be high. This new material could be developed by means of composite materials such as oxide dispersion strengthening (ODS). Since zirconia is characterized by high thermal stability, it improves on the toughness. The disadvantage is that its thermal expansion will be low. Application of pure $\mathrm{ZrO}_{2}$ component is hindered because of catastrophic fracture due to volume expansion (approximately 4\%). However, stabilizers, such as $\mathrm{Y}_{2} \mathrm{O}_{3}, \mathrm{CaO}$ or $\mathrm{MgO}$ can be employed (Glage, Weigelt, Räthel \& Biermann, 2014). Yttria on the other hand increases the wettability with steel. Stabilizing zirconia with yttria will increase the properties extensively. So, addition of zirconia partially stabilized with yttria to duplex stainless steel can produce the required characteristics by controlling the percentages of duplex stainless steel (DSS) to oxide (Sebo, Kavecky \& Stefanic, 1994; Reddy, Mukhopadhyay \& Basu, 2010). ODS plays a crucial role in determining the mechanical properties of the composite. An ideal interface should provide good adhesion and minimum boundary resistance (Hamid, Moustafa, Morsy, Khalifa \& Mouez, 2011).

Powder Metallurgy (PM) materials are extensively used for components which are subjected to sliding, rolling and abrasive wear conditions. The use of PM stainless steels in these applications is often limited by their softness and susceptibility to wear (Martin, Garcia, Blanco \& Aparicio, 2013). There have been some studies on the tribology, specifically dry sliding behaviour of PM materials (Reddy et al., 2010; Martin et al., 2013; Ceschini, Palombarini, Sambogna, Firrao, Scavino \& Ubertalli, 2006; Velasco, Martínez, Calabres, Bautista \& Abenojar, 2009). Efforts have been made to improve wear resistance using composites containing oxides. Vardavoulias, Jeandin, Velasco \& Torralba (1996) reports on the dry sliding wear mechanism for strengthened PM austenitic stainless steel with $\mathrm{Al}_{2} \mathrm{O}_{3}$ and $\mathrm{Y}_{2} \mathrm{O}_{3}$.

Holman (2008), reported that tribology is the science and technology of interacting surfaces in relative motion and the related particles. More studies on the tribological behaviour of duplex and base PM stainless steel sintered in Nitrogen atmosphere was studied by Martin et al. (2013), it was concluded that the PM duplex stainless steels show better wear resistance than base materials. In the case of this study, ceramics oxides; Zirconia partially stabilized with Yttria (PSZ) and alloying elements such as $\mathrm{Ni}$ and $\mathrm{Cr}$ has been used. The ceramic technologies have been widely used for many applications including wear resistance parts (Rosso, 2006). Through the introduction of ceramics in the matrix of metals, Metal Matrix Composites are formed (Liu, Lim, Lu \& Lai, 1994; Wei, Dare \& Pfeffer, 2002). The chromium enhances the oxidation resistance while Nickel increases toughness at low temperatures and improves corrosion and oxidation resistance.

\section{MATERIALS AND METHOD}

Duplex stainless steel (DSS) composites obtained by powder metallurgy route which has been reported elsewhere were used for this studies (Passerone, Muo1o, Novakovic \& Passerone, 2007; Dobrzanski, Brytan, Grande \& Rosso, 2007). The starting materials used for the DSS based composites consists of atomized stainless 2205 powder (average size $22 \mu \mathrm{m}$ ) whose composition is presented in table 1 , partially stabilize zirconia (PSZ, 3\% mole fraction) powder of average particle size of $50 \mathrm{~nm}$ was dispersed as reinforcement, chromium and nickel were added as alloying elements. The densities of as-received 2205, PSZ, chromium and nickel powders were $7.7 \mathrm{~g} / \mathrm{cm}^{3}, 5.18198 \mathrm{~g} / \mathrm{cm}^{3}$, $7.179 \mathrm{~g} / \mathrm{cm}^{3}$ and $8.908 \mathrm{~g} / \mathrm{cm}^{3}$ respectively. The powders with the composition shown in table 2 were mixed for $5 \mathrm{~h}$ in a Tubular ${ }^{\circledR}$ mixer for homogeneous distribution of the PSZ for dispersion strengthening. Sintering was done by High temperature High pressure uniaxial hot press in an argon environment at $1100{ }^{\circ} \mathrm{C}, 30 \mathrm{MPa}$ for $30 \mathrm{~min}$ to obtain the sintered composites. The sintered samples were ground to 1200 microns to have a flat surface. The polishing process was carried out using a smooth cloth and nano diamond suspension lubricant to achieve a mirror like image on the sample surface.

Wear was carried out at room temperature using tribometer equipment under dry sliding and wet sliding conditions. The wet sliding wear was carried out in a mine water solution of the following composition: distilled water $(1 \mathrm{~L})$, sodium sulphate $(1.237 \mathrm{~g})$, magnesium sulphate (1.99 g), calcium chloride (1.038 g) and sodium chloride (1.380 g). Tungsten carbide ball with a diameter $5 \mathrm{~mm}$ and unknown hardness was used as a counter-body with an oscillating frequency of $5 \mathrm{~Hz}$. The tests were conducted for duration of $1000 \mathrm{~s}$; the load under which the experiments were carried out was $15 \mathrm{~N}$. The coefficient of friction (COF) and the scar wear depth loss were continuously recorded by computer. 
Table 1.

Elemental composition of as-received 2205 DSS powder.

\begin{tabular}{|c|c|c|c|c|c|c|c|c|c|c|c|}
\hline Cr (\%) & Ni (\%) & Mo (\%) & Si (\%) & N (\%) & P (\%) & C (\%) & Mn (\%) & S (\%) & Fe $(\%)$ \\
\hline 22.8 & 5.1 & 3.3 & 0.77 & 0.25 & 0.014 & 0.012 & 0.98 & 0.006 & Balance \\
\hline
\end{tabular}

Source: Authors own elaboration.

Table 2.

Powder compositions for the composites.

\begin{tabular}{|l|c|c|c|c|c|c|}
\hline Sample no & $\mathbf{2 2 0 5}(\mathbf{\%})$ & $\mathbf{Z r O}_{\mathbf{2}}\left(\mathbf{Y}_{\mathbf{2}} \mathbf{O}_{\mathbf{3}}\right) \mathbf{( \% )}$ & $\mathbf{C r}(\mathbf{\%})$ & $\mathbf{N i}(\mathbf{\%})$ & - & Inclusion (\%) \\
\hline X (As received 2205) & 100.00 & - & - & - & 0.50 \\
\hline A1 & 99.50 & 0.50 & - & 0.19 & 1.50 \\
A2 & 98.50 & 0.50 & 0.81 & 0.37 & 3.00 \\
\hline A3 & 97.00 & 1.00 & 1.63 & 0.37 & 5.00 \\
\hline A4 & 95.00 & 3.00 & 1.63 & 0.56 & 5.00 \\
\hline A5 & 95.00 & 2.00 & 2.44 & & \\
\hline
\end{tabular}

Source: Authors own elaboration.

Table 3.

Relative density of the sinter.

\begin{tabular}{|l|c|c|c|c|c|}
\hline Sample & Density $\mathbf{~} / \mathbf{c m}^{\mathbf{3}}$ & Theoretical $\mathbf{g} / \mathbf{c m}^{\mathbf{3}}$ & Relative density $\%$ & Open porosity \% & Vickers Hardness HV \\
\hline X & 7.74 & 7.75 & 99.87 & 0.13 & 0.65 \\
\hline A1 & 7.68 & 7.73 & 99.35 & 91.0 & 0.49 \\
\hline A2 & 7.67 & 7.71 & 99.51 & 0.51 \\
\hline A3 & 7.68 & 7.72 & 99.49 & 0.65 \\
\hline A4 & 7.64 & 7.69 & 99.35 & 85.3 \\
\hline A5 & 7.62 & 7.66 & 99.48 & 0.52 \\
\hline
\end{tabular}

Source: Authors own elaboration.

\section{RESULTS AND DISCUSSION}

The compositions of admix were presented in table 2 while the density and hardness values of the developed composites are presented in table 3.

Table 3 shows that densification is a function of reinforcement; i.e. densification was increasing with percentage increase in the reinforcement. Though, the densification was not that significant, possibly due to the particle size ratio. However, the achieved densification results shown in figure 1 were possible due to particle size of the reinforcement and good wettability of $\mathrm{Zr}$ with Fe (Sebo et al., 1994; Passerone et al., 2007). The PSZ were of nano size (50 nM), they were able to fill up the pores created by the DSS powders as a result of proper and adequate mixing, thereby reducing the overall porosity of the sinter sample. It has been shown in particular that particle size ratio has a prominent effect on the densification kinetics (Daumann, Webber, Anlauf \& Nirschl, 2011). This will in turn have effect on the overall properties of the sintered component. $\mathrm{Cr}$ and $\mathrm{Ni}$ addition also contributed to the densification obtained. Given that $\mathrm{Cr}$ is abrasive therefore tends to reduce (Ming et al., 2010, Passerone et al., 2007; Chen, Li, Liu \& Cao, 2007). $\mathrm{Ni}$, on the other hand, considering the melting point, melts and flow by capillary to fill up the open pores created within the composite (Chen et al., 2007). This was evident in the densification presented in table 3. The presence of $\mathrm{Y}_{2} \mathrm{O}_{3}$ as stabilizer for the PSZ also influenced densification (Chawla \& Chawla, 2006; Rachman, Amit \& Claude, 2009). The results of the densification showed that the composites were well densesified at the sintering conditions chosen.

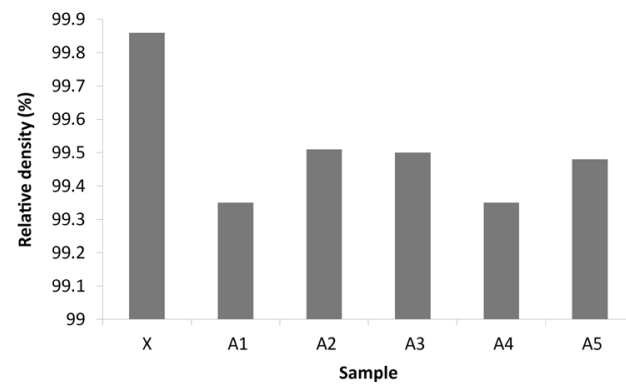

Figure 1. Densification obtained after sintering.

Source: Authors own elaboration. 
The influence of $\mathrm{Ni}$ addition was also observed on the hardness of the developed composites. It was expected that hardness should be increasing with increment in PSZ addition and $\mathrm{Cr}$, which was actually observed from sample $\mathrm{X}$ and $\mathrm{A} 1$ but, the addition of $\mathrm{Ni}$ has influenced the hardness such that addition of $\mathrm{Ni}$ must have compromised the hardness for toughness (Younesi \& Bahrololoom, 2010). This was evident in the hardness trend observed as the percentage composition of the Ni was increasing with PSZ and $\mathrm{Cr}$ addition as shown in figure 2.

Figure 3 shows the coefficient of friction for the sintered as received 2205 DSS and its ODS composites (table 2), when sliding against the Tungsten Carbide ball in dry conditions. The COF is determined by the ratio of the friction force to the loading force on the ball. The results show that the COF increases with increasing $\mathrm{ZrO}_{2}$ $\left(\mathrm{Y}_{2} \mathrm{O}_{3}\right)$, Ni and $\mathrm{Cr}$ content. Higher friction means higher wear rate and therefore the lower the wear resistance. On the other hand, the sample with the lowest contents of $\mathrm{ZrO}_{2}\left(\mathrm{Y}_{2} \mathrm{O}_{3}\right)$, Ni and $\mathrm{Cr}$ (i.e. sample A2), showed lower $\mathrm{COF}$, it behaved similarly to sample A1 which contains only a small amount of Zirconia with no further addition of Cr-Ni. Since Zirconia incorporates strengthening effects, it increases the hardness of the composite as its content is increased. Continued reciprocating motion of the WC ball on the surfaces requires breaking of the bond junctions. The more the percentage composition of the hard phase (PSZ) present, the more the possibilities that more of it will be broken initially and when broke off, they also contribute to the wearing of the subsequent substrates by grooving it. There will be accelerated plastic deformation with increasing volume fraction of the ceramic reinforcement. Another factor could be localized debonding or fracture of ceramic particles (Glarge et al., 2014) This was evident and characterized the SEM image obtained as shown in figure 5 before the formation of the smeared layer which prevented further grooving. Figure 5 shows the worn surfaces samples A1-A5 and sintered as received DSS 2205 under dry sliding load of $15 \mathrm{~N}$ at $5 \mathrm{~Hz}$. The presence of grooves and the tungsten carbide caused by motion is evident and confirmed by EDX spectrum of the worn surface; these are the shear lips / scaly-like areas referred to as transferred layer (Younesi \& Bahrololoom, 2010). The reason for the formation of shear lips was results of the mechanism of the tungsten ball during wear. This layer was gotten by the top layer that got worn off, broken into small powders within the wear tracks and experience repeated compressing, twisting, shearing and could be re-smeared onto the wear surface. Furthermore, dark and light areas were observed for all the samples. The EDS analysis showed that the light areas were Zirconia (PSZ). The micrographs of the two samples showed visible grooves, due to the amount of dispersed Zirconia, the material tend to be hard but considering the load, third-body wear mechanism was introduced. This is in agreement with (Younesi \& Bahrololoom, 2010). The wear mechanisms for the specimens generally were form of abrasive wear that occurs when hard particles become embedded in soft surface areas. The high wear load caused breaking of brittle hard phase in the composites surface thereby activating third body wear mechanism.

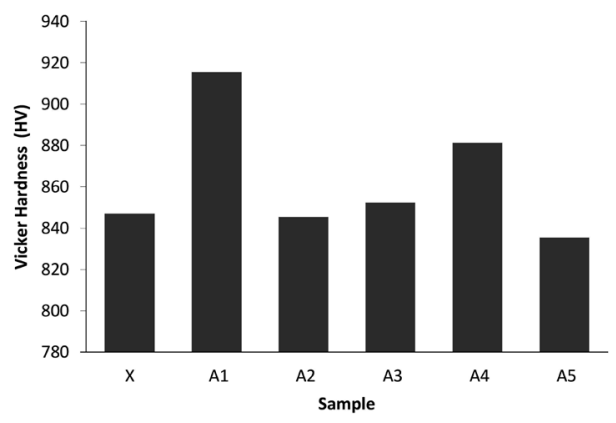

Figure 2. Vickers hardness of 2205 DSS composites developed. Source: Authors own elaboration.

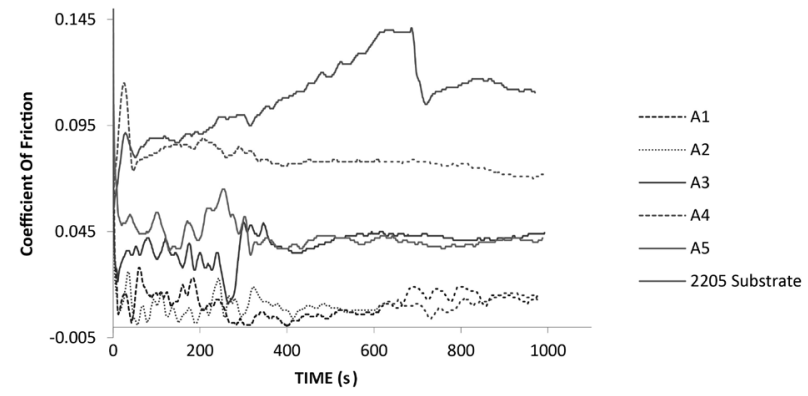

Figure 3. Dry Wear Results of DSS 2205 composites under wear load of $15 \mathrm{~N}$. Source: Authors own elaboration.

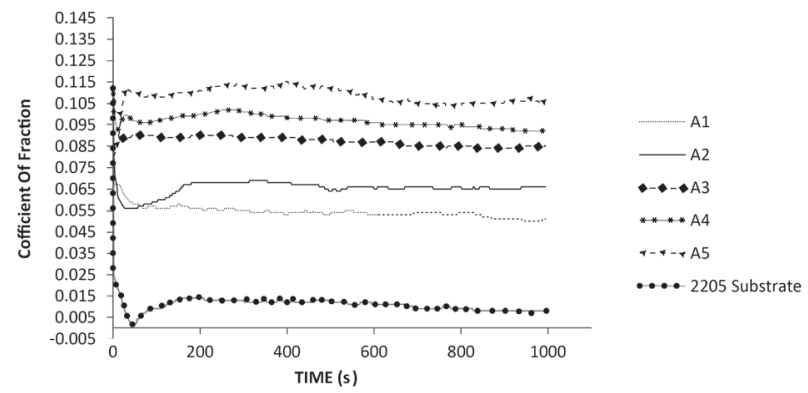

Figure 4. Wet wear results of DSS 2205 composites under wear load of $15 \mathrm{~N}$. Source: Authors own elaboration. 
Figure 4 shows the coefficient of friction with time for the 2205 composites under wet condition in a simulated mine water under wear load of $15 \mathrm{~N}$. The results indicated that sintered as-received 2205 had the least COF while A5 retained its least wear property. This shows that percentage increase of the PSZ also increase the $\mathrm{COF}$ of the composites. It was expected that the COF should be lowered because of the hardness with the increasing PSZ content, however, this increase in the COF could possibly be linked to two different factors; (i) the high load which could activate the third body wear mechanism (Younesi \& Bahrololoom, 2010) and, (ii) corrosion attack on the substrate must have weaken the composites thereby increases the wearing of the composites by the combine actions of reciprocating movement of the counter body and the particles of PSZ being broken which in-turn grove the attacked surface by increasing the COF. The effect of which are shown on the SEM micrographs, figure 8. In this case, the wear could be termed 'corrosion induced wear' since the worn effect could have been influenced by corrosion due to the chemical activities between the substrate and the environment.

The EDS also confirmed that the scaly-like areas observed on the SEM micrographs had some content of tungsten, which proved that there was volume loss on the tungsten ball used as counterbody.

The volume loss on the counterbody caused the weight gain on the test composite which informed the choice of another form of wear analysis; TABER INDEX, when materials of same base material shows inconsistency, i.e. during wear experiment, when some materials are gaining weight while some are losing weight under the same conditions, COF alone may not be a realistic parameter for wear resistance evaluation. There is possibility that when a hard material glides on another hard material, it may produce friction but there will not be much wear, it is therefore advisable to corroborate $\mathrm{COF}$ with Taber Index. Taber index measurement is based on weight loss measurement; this technique measures how much material has been removed by abrasion, and is usually reported in milligram. Taber wear index indicates the rate of wear, and is calculated by measuring the loss in weight (in milligrams) per thousand cycles of abrasion resistance (Taber Abraser, n.d.). The lower the index value, the better the wear resistance of the material. Better still, material with negative values has the best properties as it is an indication that the material instead of wearing off, continue to gain weight as a result of adhesion of material from the counterbody to the test piece.

$$
I=[(A-B) \times 1000] / C .
$$

Where $I$ is the wear index, $A$ is the weight before experiment, $B$ is the weight after experiment, $C$ is the number of cycles.

From table 4, it was observed that sample A2 has the least value of index. Comparing this result with $\mathrm{COF}$ in figure 3, it was also observed that sample A2 has the least COF which means sample 2 has the best wear property of all the develop composites.

From table 3 , it was observed that sample A2 has the least value of Taber Index while A5 has the highest value. Comparing this result with figure 3 , it was observed that sample A2 has the least COF while A5 has the highest, which means, sample A2 has the best wear property but A5 has the least wear property of all the composites. Figure 5 (b) also confirmed this with larger areas of transferred scaly-like layers. Also the plot of wear depth revealed that sample A2 has the least value of wear depth as indicated by figure 6 . The plot of weight loss against time (figure 7) also corroborated the fact that dispersion of PSZ greatly reduced the degree of wear on the composites with sample A2 having the best wear property.

\begin{tabular}{|c|c|c|c|c|}
\hline Sample & Weight before (mg) & Weight after (mg) & Taber Index & Wear depth \\
\hline $\mathrm{x}$ & 3.04927 & 3.04924 & 0.010 & 0.06 \\
\hline A1 & 2.62194 & 2.62160 & 0.0113 & 0.003 \\
\hline A2 & 2.46258 & 2.46261 & -0.01 & 0.0025 \\
\hline A3 & 3.0815 & 3.08133 & 0.06 & 0.0035 \\
\hline A4 & 3.17141 & 3.17120 & 0.07 & 0.007 \\
\hline A5 & 2.9372 & 2.9325 & 1.57 & 0.018 \\
\hline
\end{tabular}

Source: Authors own elaboration. 


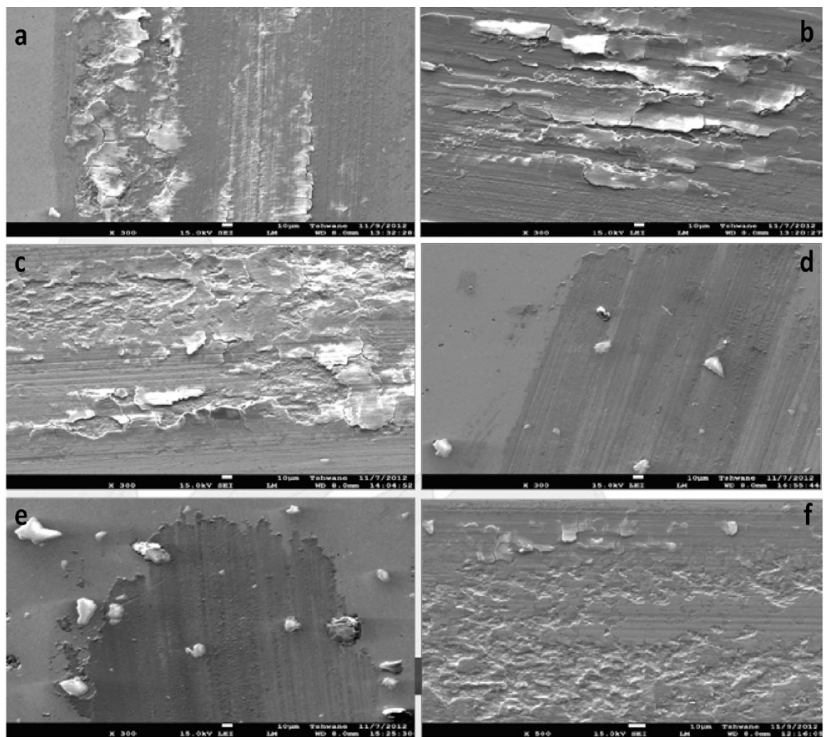

Figure 5. SEM images of the worn surfaces after dry sliding of a) A1, b) A2, c) A3, d) A4, e) A5 and $f) X$.

Source: Authors own elaboration.

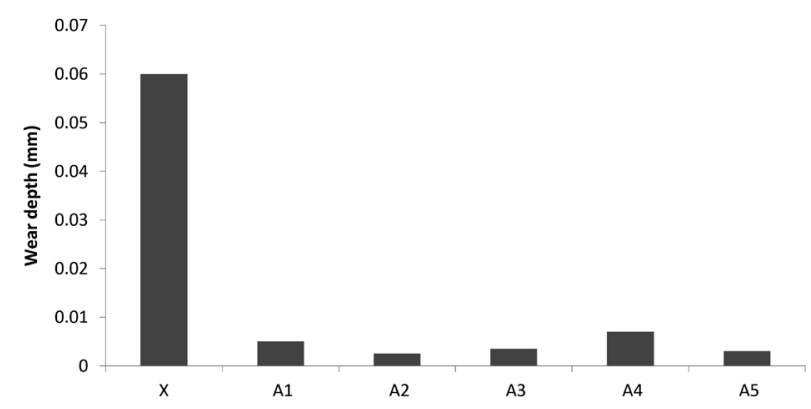

Figure 6. Wear depth for the 2205 DSS composite. Source: Authors own elaboration.

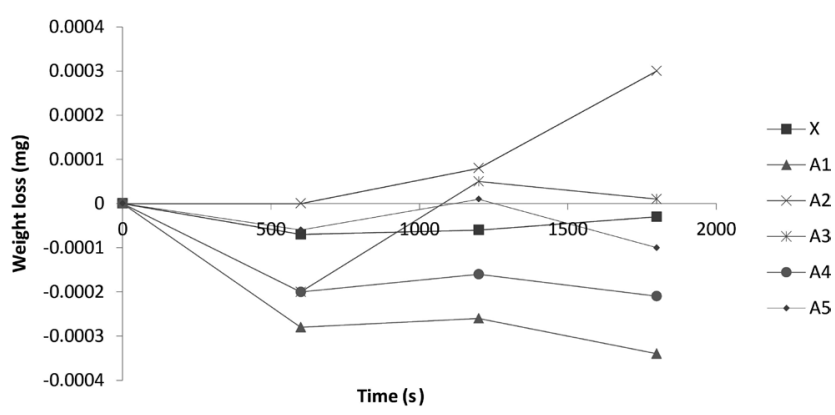

Figure 7. Variation of weight loss with time for dry sliding under $20 \mathrm{~N}$. Source: Authors own elaboration.
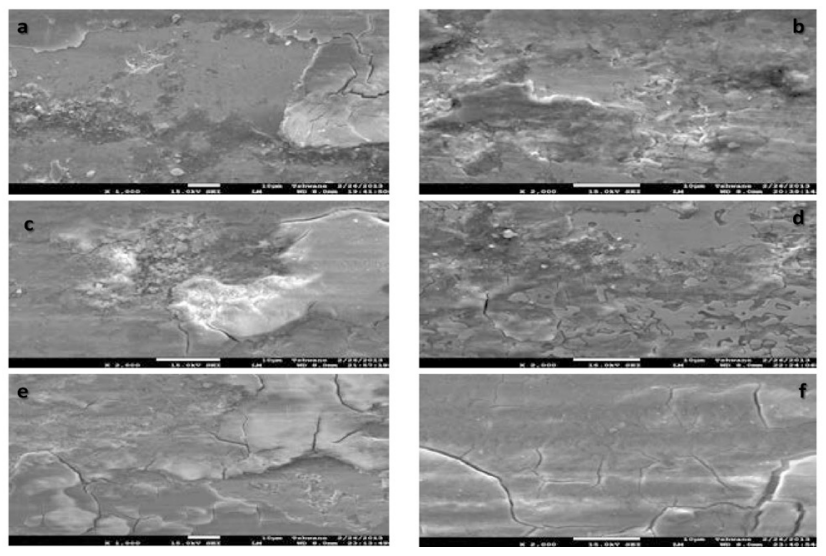

Figure 8. SEM images of the worn surfaces after wet sliding of a) A1, b) A2, c) A3, d) A4, e) A5 and f) X.

Source: Authors own elaboration.

\section{CONCLUSION}

Tribological behaviour of PM Oxide Dispersion Strengthened (ODS) DSS composite was studied using a tribometer with a ball on disc. It was concluded that:

Wear behaviour of 2205 DSS composite depends on the composition of the material; small amount of PSZ incorporated within the matrix of the composite enhances wear property but too much of it could be detrimental, as deformation behaviour of the matrix and the reinforcements are not similar

$\mathrm{COF}$ as a measure of wear property was complimented with Taber Index measurement to validate the wear property of the composites. It was found that sample A2 with $0.5 \% \mathrm{PSZ}, 0.81 \% \mathrm{Cr}$, and $0.19 \% \mathrm{Ni}$ has the best wear property.

The hardness of the composite was greatly influenced by the addition of PSZ and Cr but Ni addition reduce the hardness and compromising it for toughness.

\section{ACKNOWLEDGEMENTS}

The authors wish to acknowledge the financial support received from Tshwane University of Technology (TUT), Pretoria, South Africa, National Research Foundation, South Africa (NRF) and the Federal University of Technology, Akure (FUTA). The authors thank Lepule M. and Tshepe T. S. for the help in the experiments. 


\section{REFERENCES}

Campos, M., Bautista, A., Caceres, D., Abenojar, J. \& Torralba, J. M. (2003). Study of the interfaces between austenite and ferrite grains in P/M duplex stainless steels. Journal of the European Ceramic Society, 23(15),2813-2819.

Ceschini, L., Palombarini, G., Sambogna, G., Firrao, D., Scavino, G. \& Ubertalli, G. (2006). Friction and wear behaviour of sintered steels submitted to sliding and abrasion tests. Tribology International, 39, 748-55.

Chawla, N. \& Chawla, K. K. (2006). Metal matrix composites. New York: Springer.

Chen, H., Li, Y. Y., Liu, Y. B. \& Cao, X. J. (2007). Influence of chromium on microstructure and sintering properties of FeNiMoCu system prealloyed powders. Journal of Materials Processing Technology, 182, 462-468.

Datta, P. \& Upadhyaya, G. S. (2001). Sintered duplex stainless steels from premixes of 316L and 434L powders. Materials Chemistry and Physics, 67(1-3), 234-242.

Daumann, B., Webber, J. A., Anlauf, H. \& Nirschl, H. (2011). Discontinuous powder of nanoscale particles. Chemical Engineering Journal, 167(1), 377-387.

Dobrzanski, L. A., Brytan, Z., Grande, M. \& Rosso, M. (2007). Properties of Duplex Stainless steels made by Powder Metallurgy. Archives of Materials Science and Engineering, 28(4), 217-223.

Glage, A., Weigelt, C., Räthel, J. \& Biermann, H. (2014). Fatigue Behaviour of Hot Pressed Austenitic TWIP Steel and TWIP Steel/Mg-PSZ Composite Materials. International Journal of Fatigue, 65(2014), 9-17.

Hamid, Z. A., Moustafa, S. F., Morsy, F. A., Khalifa, N. A. A. \& Mouez, F. A. (2011). Fabrication and characterization copper/diamond composites for heat sink application using powder metallurgy. Journal of Natural Science, 3(11), 936-942.

Holman, J. (2000, 30 may). Energy Crisis drives increased interest research in Tribology. Engineering News. Recuperado de http://www.engineeringnews.co.za/ article/energy-crisis-drives-increased-interest-research-in-tribology-2008-05-30

Liu, N. B., Lim, S. C., Lu, L., \& Lai, M. O. (1994). Recent development in the fabrication of metal matrix-particulate composites using powder metallurgy techniques. Journal of Materials Science, 29(8), 1999-2007.

Martin, F., García, C., Blanco, Y. \& Aparicio M. L. (2013). Tribocorrosion behaviour of Powder Metallurgy duplex stainless steel sintered in Nitrogen. Tribology International, 57, 76-85.
Ming, L., Zhangjian, Z., Pei, H., Lu, L., Yingli, X. \& Changchun, G. (2010). Microstructure and mechanical property of $12 \mathrm{Cr}$ oxide dispersion strengthened ferritic steel for fusion application. Fussion Engineering and Design, 85(2010), 1573-1576.

Passerone, A., Muolo, M. L., Novakovic, R. \& Passerone, D. (2007). Liquid matel/ ceramic interactions in the $(\mathrm{Cu}, \mathrm{Ag}, \mathrm{Au}) / \mathrm{ZrB}$ systems. Journal of European Ceramic Society, 27(2007), 3277-3285.

Rachman, C., Amit, S. \& Claude, E. (2009). Densification of nanocrystalline $\mathrm{Y}_{2} \mathrm{O}_{3}$ ceramic powder by spark plasma sintering. Journal of the Ceramic Society, 29(2009), 91-98.

Reddy, K. M., Mukhopadhyay, A. \& Basu, B. (2010). Microstructure-mechanicaltribological property correlation of multistage spark plasma sintered tetragonal $\mathrm{ZrO}_{2}$. Journal of the European Ceramic Society, 30(2010), 3363-3375.

Rosso, M. (2006). Ceramic and metal matrix composites: route and properties. Achievements in Mechanical and Materials Handling, 175, 304-375.

Sebo, P., Kavecky, S. \& Stefanic, P. (1994). Wettability of Zirconia-coated carbon by aluminium. Journal of Materials Science Letters, 13(1994), 592-593.

Sulima, I., Klimczyk, P. \& Hyjek, P. (2009). The influence of the sintering conditions on the properties of the stainless steel reinforced with TiB2 ceramics. Archives of Materials Science and Engineering, 39(2), 103-106.

Vardavoulias, M., Jueandin, M., Velasco, F. \& Torralba, J. M. (1996). Dry sliding wear mechanism for P/M austenitic stainless steels and heir composites containing $\mathrm{Al}_{2} \mathrm{O}_{3}$ and $\mathrm{Y}_{2} \mathrm{O}_{3}$ particles. Tribology International, 29(6), 499-506.

Velasco, F., Martínez, M. A., Calabres, R., Bautista, A. \& Abenojar, J. (2009). Fric tion of PM ferritic stainless steels at temperatures up to $300{ }^{\circ} \mathrm{C}$. Tribology International, 42(2009), 1199-205.

Wei, D., Dave, R. \& Pfeffer, R. (2002). Mixing and characterization of nanosized powders: An assessment of different techniques. Journal of Nanoparticle Research, 4, 21-41.

Taber Abraser (Abrader) (n.d.). Recuperado de www.taberindustries.com/taberrotary-abraser

Younesi, M. \& Bahrololoom, M. E. (2010). Optimization of wear resistance and toughness of hydroxyapatite nickel free stainless steel new bio-composites for using in total joint replacement. Materials and Design, 31(2010), 234-243.

Zhoungchun, C., Takenobu, T., Keisuke, I. \& Tadasu, M. (2000). The influence of powder particle size on microstructural evolution of metal-ceramic composite. Scripta mater, 43(2000), 1103-1109. 